\title{
Development and Application of Thermo-mechanical Control Process Involving Ultra-fast Cooling Technology in China
}

\author{
Zhaodong WANG, Bingxing WANG, ${ }^{*}$ Bin WANG, Yong TIAN, Tian ZHANG, Guo YUAN, Zhenyu LIU and \\ Guodong WANG
}

State Key Laboratory of Rolling and Automation, Northeastern University, Shenyang, 110819 China.

(Received on January 30, 2019; accepted on July 4, 2019)

\begin{abstract}
Thermo-mechanical control process (TMCP) is an important and effective rolling technology for microstructural control to obtain excellent mechanical properties, such as high strength, excellent toughness and other performances, which consists of controlled hot rolling and controlled cooling. RAL laboratory in China has been making efforts to develop ultra-fast cooling (UFC) technology, which is referred as the core technology for New Generation (NG)-TMCP. The ongoing development of UFC technology, with high cooling capacity and uniform cooling control, provides the effective control of cooling paths for a wide range of water-cooled steel strips and plates. Here, the development and characterization of UFC technology are introduced, and advanced cooling system (ADCOS) for the UFC equipment will be elucidated as well. Moreover, the superior mechanical properties can be obtained by inter-pass cooling technology during rolling processing, which is characterized by water-cooling between controlled rolling passes and further reheating due to the internal heat capacity of plate on its own. The resultant theory and technology can achieve resource conservation, energy saving and emission reduction for green products in the manufacturing process for upgrading of steel industry in China.
\end{abstract}

KEY WORDS: thermo-mechanical control process (TMCP); ultra-fast cooling (UFC); advanced cooling system (ADCOS); strip and plate; inter-pass cooling.

\section{Introduction}

Iron and steel industry plays a key role in supportive of China's industrializing progress, making considerable contribution to economic growth in China. However, China's steel industry is now facing with a challenging dilemma of resource dependence, energy consumption, and environment pressure. According to the National Key Research and Development Programs during the 13th Five-Year Plan, the transformation and upgrading of steel industry have been explicitly addressed with the multi-purpose solutions: tackling overcapacity, restructuring large enterprises, restricting disorderly competition, promoting technological innovation and environment-friendly development. Innovated design in alloy-saving and high-performance steel products can also help users to achieve green development. Thus, the attention has been drawn on developing environment-friendly and high-performance hot-rolled steel products, which would consume much less resource, energy, and alloys, in order to attain the goal of green manufacture. ${ }^{1,2)}$ This is the key factor and natural trend in the sustainable development of iron and steel industry in China.

Thermo-mechanical control process (TMCP), being one of the greatest steel technologies in the 20th century, has been extensively applied in production, improving strength,

* Corresponding author: E-mail: wbxang@126.com

DOI: https://doi.org/10.2355/isijinternational.ISIJINT-2019-041 toughness and performance remarkably. It has been practically proved effective in saving energy, simplifying processing operation and developing new steel products. ${ }^{3-5)}$ Recently, a new generation of TMCP was successfully developed based on ultra-fast cooling (UFC) by the State Key Laboratory of Rolling and Automation (RAL) at Northeastern University in China. ${ }^{6-8)}$ The innovated technology utilizes combined strengthening mechanism involving grain refinement, precipitation, transformation and solid solution, exploiting great potential of hot-rolling and cooling. The new TMCP technology makes it possible for enormous reduction in alloy-addition and considerable simplification in the process that can produce distinguished strip $\&$ plate products with better mechanical properties as well as application performance. This is of great significance for China's steel industry to improve both energy efficiency and product performance by developing energy-saving hotrolled steel products.

\section{Research and Development of Ultra-fast Cooling Technology and Equipment}

\subsection{Historical Review of Ultra-fast Cooling for Steel Strips and Plates}

Since the end of the last century, CRM, the top steel research institution in Europe, had carried out in-depth studies in ultra-fast cooling process and developed the ultra-fast cooling system for hot-rolled steel strips and 
plates in cooperation with steel producers and metallurgical industrial manufacturers, such as Hoogovens-UGB, SMS, VAI, etc. ${ }^{9)}$ As illustrated in Fig. 1, ${ }^{9.10)}$ the length of ultrafast cooling equipment for hot rolling strip was usually in the range of 7-12 $\mathrm{m}$ and it could be installed directly after the finishing rolling mill or after laminar cooling equipment, in conjunction with the laminar cooling system. In this cooling system, the cooling rate could reach $300^{\circ} \mathrm{C} / \mathrm{s}$ for $4 \mathrm{~mm}$ thick strip. This equipment consisted of several headers with closely arranged nozzles. Ultra-fast cooling process was obtained by increasing water pressure and arranging high density of nozzles, which realized the high efficient heat transfer in unit time between water and hot steel strip through increasing the water impact on the gas film.

Super-OLAC H (Super On-Line Accelerated Cooing for Hot Strip Mill) system, investigated by JFE Steel Corporation, could realize ultra-fast cooling of $700^{\circ} \mathrm{C} / \mathrm{s}$ for $3 \mathrm{~mm}$ thick hot rolling strip. The $780 \mathrm{MPa}$-class NANO-HITEN steel was developed by JFE with good ductility, high elongation and hole expanding ratio, which was viewed as a typical representative product of ultra-fast cooling technology. ${ }^{11)}$ The microstructure of NANO-HITEN consisted of ferrite and $\mathrm{TiC}$ particles with size of $1-5 \mathrm{~nm}$ distributing on the ferrite matrix. Figure 2 shows the characteristics of the product quality of the NANO-HITEN steel. ${ }^{11,12)}$

In order to obtain high cooling rate, China Steel Corp in Taiwan and Baosteel in Shanghai developed the enhanced laminar cooling device. The enhanced laminar cooling device was developed from the laminar cooling device by increasing the density of muzzles on the upper part. The water flow of the enhanced laminar cooling device was 2 times of the ordinary laminar cooling device. Compared with the ordinary laminar cooling device, more laminar water columns penetrate the steam film and contact directly with the hot steel strip, increasing the heat transfer rate. The lower part of the enhanced laminar cooling device was similar to the ordinary laminar cooling device. The only difference is that the enhanced laminar cooling device could provide more water to increase promote the heat transfer process. Productive practices indicate that a high cooling rate of $200^{\circ} \mathrm{C} / \mathrm{s}$ could be reached with the enhanced laminar cooling device for $3 \mathrm{~mm}$ thick strip with moving speed of $9.5 \mathrm{~m} / \mathrm{s}$. Moreover, POSCO in South Korea also developed their own ultra-fast cooling technique, HDC (High Density Cooling). Combining control rolling and ultra-fast cooling, a patent on low-cost and ultra-high strength pipeline steel produce was developed. The yield strength of pipeline steel could reach $930 \mathrm{MPa}$ (X130) and the addition of precious elements such as Mo decreases as well.

In the field of medium and heavy plate production, ultra fast cooling system are also developed in significant characteristics by steel manufacturing enterprises, such as JFE Steel, Nippon Steel, Sumitomo Metal, Voestalpine and SMS, etc. ${ }^{13,14)}$ In 1978, JFE Steel began on-line acceler-

(a)

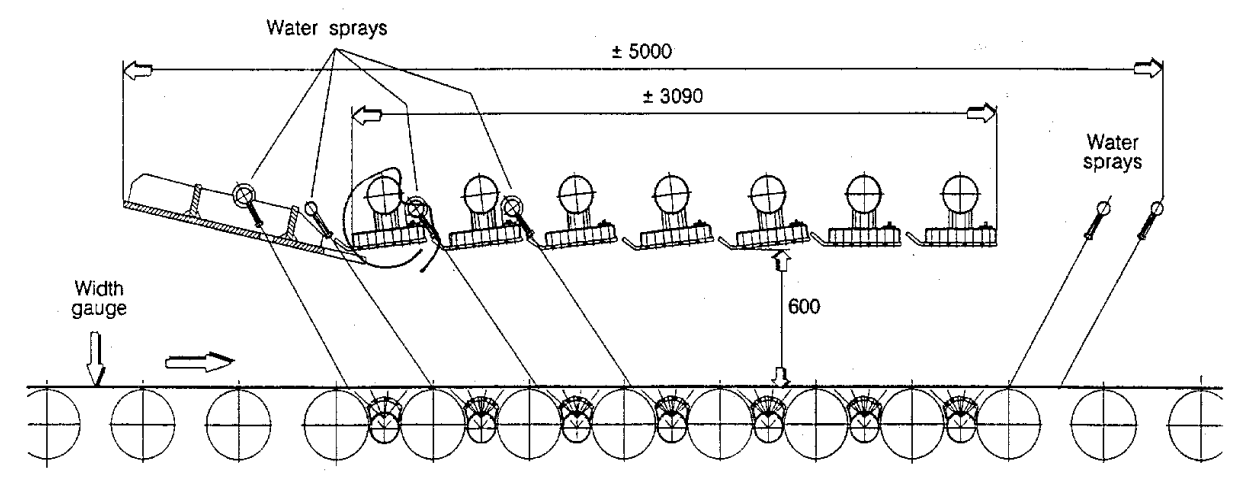

(b)

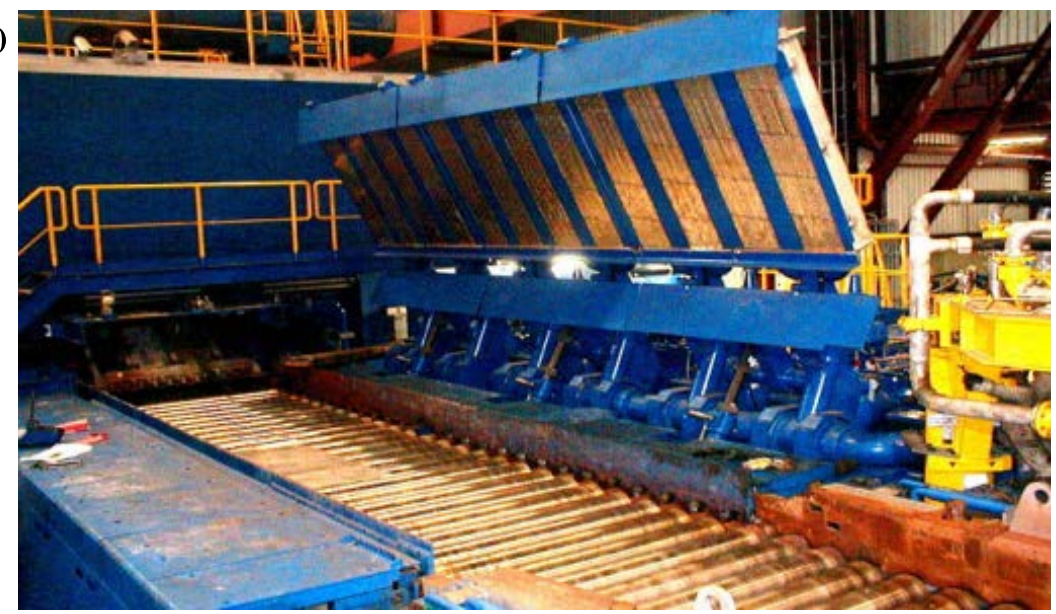

Fig. 1. UFC system developed by CRM (a) and UFC device for hot strip rolling in Thyssenkrupp steel (b). (Online version in color.) 

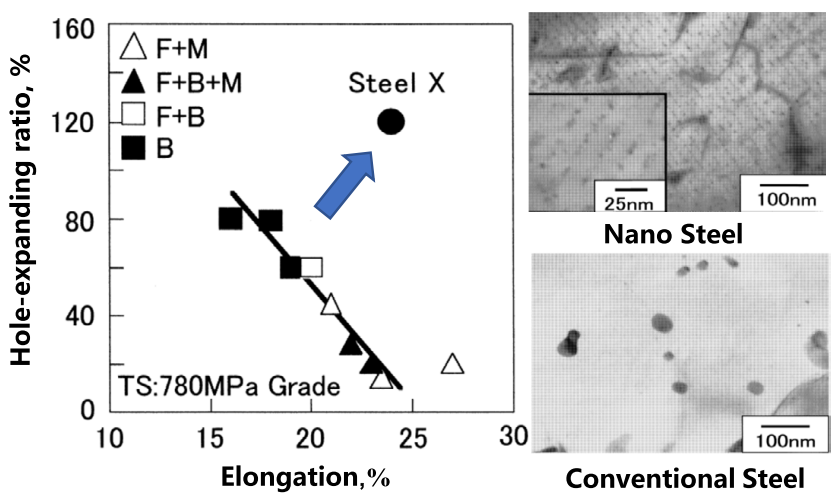

Fig. 2. NANO-HITEN steel developed by applying nanometersize precipitates. (Online version in color.)

(a)

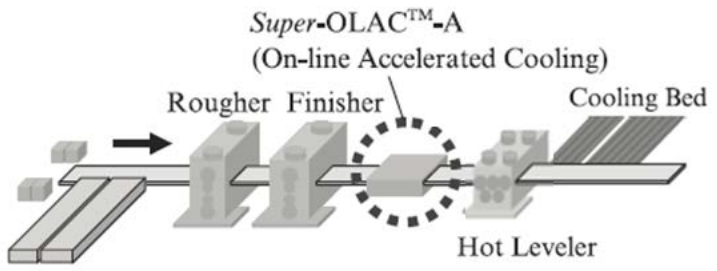

Furnace

(b)

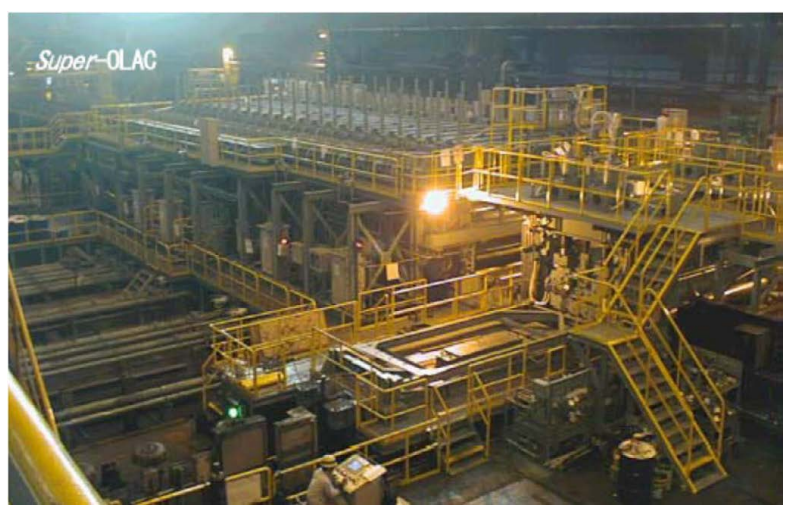

Fig. 3. Layout of on-line accelerated cooling facility in Fukuyama (a) and equipment for thick plate (b). (Online version in color.)

ated cooling (OLAC) at a plate mill. As a result of tireless development efforts, Super-OLAC was developed in 2001, which dramatically expands the capabilities of conventional cooling technology. The core technology of Super-OLAC is to realize cooling in the nucleate boiling condition over the full temperature range. Both high cooling intensity and cooling uniformity of the plate can be obtained at the same time. The Super-OLAC layout and equipment were shown in Fig. 3. ${ }^{15,16)}$ The cooling capacity of SuperOLAC was two times as much as conventional cooling technologies from $600^{\circ} \mathrm{C}$ to $1000^{\circ} \mathrm{C}$, and the temperature distribution of steel plates remain uniform after the spray cooling stopped, making the residual stress of the plate during TMCP process in the same level as normal rolling process. JFE developed a series of high quality steel plate by Super-OLAC technology, such as high-strength steel with excellent welding performance, high-rise building steel, EASYFAB steel, pipeline steel, etc. Besides, Nippon Steel and Sumitomo Metal also developed new generation cooling system with their own distinctive characteristics based on their original control cooling equipment in recent

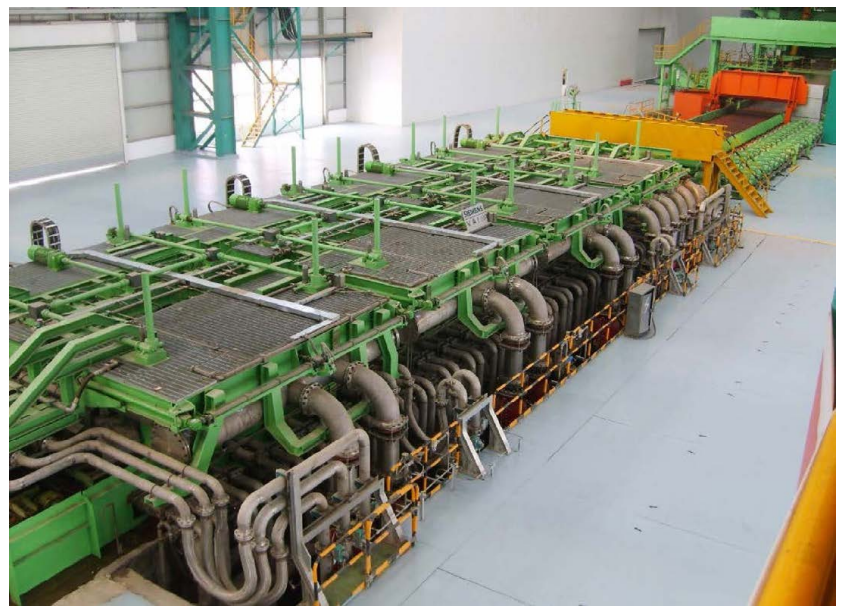

Fig. 4. Mulpic intensive plate cooling system. (Online version in color.)

years. Nippon Steel introduced CLC- $\mu$ system with ultra fast cooling function, which was applied to develop and produce high performance and high quality steel plate in 2005. Sumitomo Metal changed one DAC production line as the DAC- $\mu$ system with ultra fast cooling function in medium plate production in 2010 .

MULPIC equipment was developed by Voestalpine VAI and CRM Group for Multi-Purpose Interrupted Cooling. Intensive configuration structure of cooling header and pressure addition measure of cooling water were adopted in MULPIC system, ${ }^{17}$ ) which could form a turbulent flow on the surface of the plate, with the heat flux of $5 \mathrm{MW} /$ $\mathrm{m}^{2}$. Multiple cooling ways could be realized to produce the wider and thicker plates, due to the larger adjustable range of cooling flow. Meanwhile, some methods and technologies for uniform cooling, such as water crown, longitude track and mask control, and water ratio adjustment, were adopted in MULPIC, which could provide the feasibility of uniform control for steel plate microstructures and properties under the condition of high intensity cooling. A series of high comprehensive performance plates were produced by MULPIC cooling system, such as construction steel, container steel, bridge steel, high strength ship plate, pipeline steel, vessel steel, and low alloy high strength steel plates, etc. This technology has been licensed to SIEMENSVAI, combining cooling mode of direct quenching (DQ) and accelerated cooling (ACC) for plates, as shown in Fig. 4. ${ }^{18,19)}$ Besides, POSCO group in Korea also developed ultra fast cooling system in heavy plate production based on advanced cooling equipment.

\subsection{Research of Advanced Cooling System (ADCOS) in China}

Since 21th century, scientific institutions in China have increased research efforts on the ultra-fast cooling (UFC) technology, and made a rapid development of cooling technology and equipment in theory, manufacture and application. RAL Laboratory has led to research and develop the UFC technology for hot-rolled strips and plates in domestic steel industry, including laboratory experiment, pilot plant test and industrial development processes. The relevant prototype of experimental device, industrial equipment in pilot and complete industrial technology and equipment were 
developed in recent 10 years. $^{20-23)}$

The uniformity control in the condition of high cooling intensity has been a bottleneck for high strength steels by TMCP technology. In order to acquire higher cooling strength and homogeneity, the inclined jet impingement cooling technology was adopted in ADCOS system for hot rolling strips and plates instead of conventional laminar cooling. ${ }^{24)}$ In this ultra-fast cooling system, slit nozzles and high-density nozzles with the particular jet pattern make cooling water form a uniformly continuous banding impact zone, as shown in Fig. 5, which can break through the vapor film adhering to the hot steel surface under a certain pressure and turn heat transfer into effective nucleate boiling and forced convection accordingly, leading to achieve the goal of effective heat transfer. The heat transfer flow of jet impingement is divided into two distinct regions, a stagnation region and a wall jet region. ${ }^{25,26)}$ The thickness of flow-boundary-layer and thermal-boundary-layer in stagnation region is highly reduced so that forceful heat transfer and mass transfer were generated efficiently. In the wall jet region, the turbulence between wall jet and surrounding air is transferred to the boundary layer of heat transfer surface, as a result that the heat transfer efficiency in the wall jet region is higher than the efficiency in the parallel flow region.

The cooling capability of ADCOS system is more than two times as that of the conventional laminar cooling and the instant cooling rate in a large temperature range can be controlled effectively, which satisfy the needs of the intensity of conventional laminar cooling, ultra fast cool-

(a)

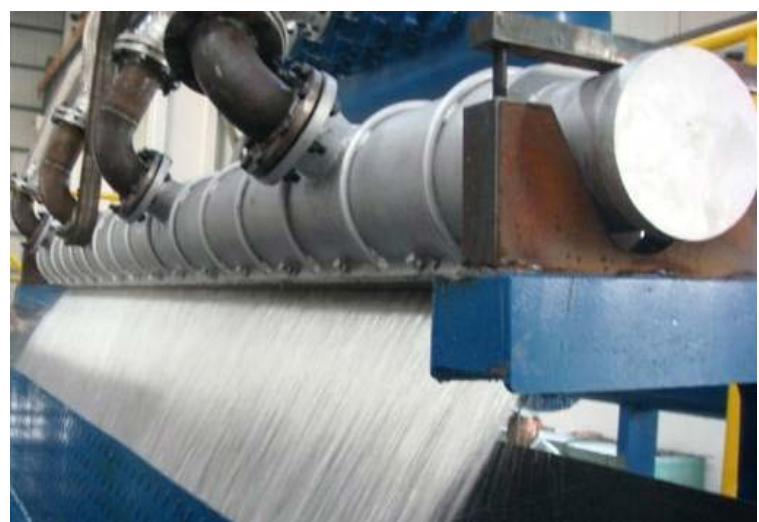

(b)

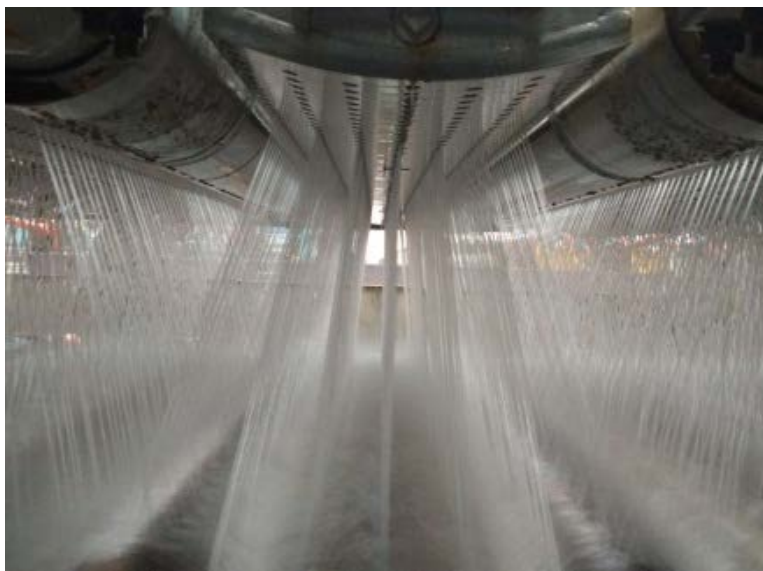

Fig. 5. Actual images of the slit nozzle (a) and high density nozzle (b). (Online version in color.) ing and direct quenching. The maximum cooling rates for steel plates with thickness of $10 \mathrm{~mm}$ and $50 \mathrm{~mm}$ are more than $120^{\circ} \mathrm{C} / \mathrm{s}$ and $10^{\circ} \mathrm{C} / \mathrm{s}$, respectively. Figure 6 shows the comparison of cooling capacity and cooling uniformity between inclined jet impingement cooling and conventional accelerated cooling.

The cooling capacity reflects the intensity or power of the cooling, including important parameters such as water pressure and flow density, and the most important performance of cooling capacity is the water cooling rate. Currently, inclined jet and laminar cooling are the most widely used cooling methods in industrial applications. Due to technical indicators of industrial production, the maximum water pressure of the inclined jet cooling is up to $0.5 \mathrm{MPa}$, while the laminar cooling is $\leq 0.2 \mathrm{MPa}$. The flow density range of inclined jet and laminar cooling is 0-1666 L/ $\left(\min \cdot \mathrm{m}^{2}\right)$ and $0-952 \mathrm{~L} /\left(\mathrm{min} \cdot \mathrm{m}^{2}\right)$, respectively. The cooling rate depends on factors such as plate thickness and water temperature, and the rang of inclined jet and laminar cooling is $0-120^{\circ} \mathrm{C} / \mathrm{s}$ and $0-60^{\circ} \mathrm{C} / \mathrm{s}$, respectively. Temperature difference along the length and the width after cooling reflects cooling uniformity of the whole steel plate. Excellent cooling uniformity of inclined jet cooling further improves the flatness of steel plate.

Based on ultra fast cooling equipment, the base automation and technological process automation control system are established with multi-stage cooling path and multiple cooling modes. The system can achieve accurate control of cooling path by setting processing parameters automatically, such as start cooling temperature, finish cooling temperature and cooling rate, according to the requirements of material microstructure and performance. The application of this UFC system can effectively improve the cooling uniformity of products and reduce deterioration tendency of plate shape, especially for low carbon bainite steel plates, such as high grade pipeline steel and high strength structure steel, which are prone to form shape defects. Figure 7 shows the plate shape of high grade pipeline steel and high strength structural steel developed by ADCOS system.

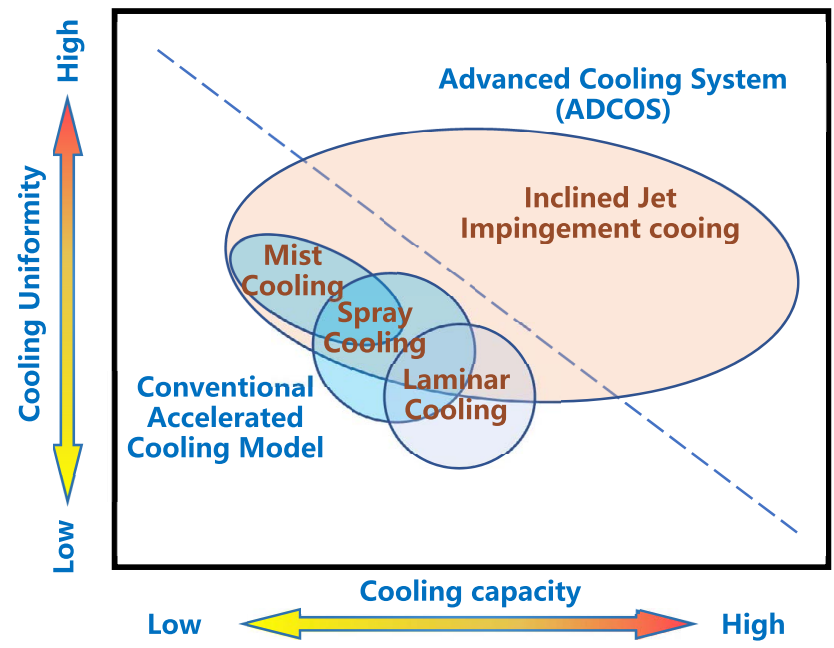

Fig. 6. Comparison of cooling capacity and cooling uniformity between inclined jet impingement cooling and conventional accelerated cooling. (Online version in color.) 

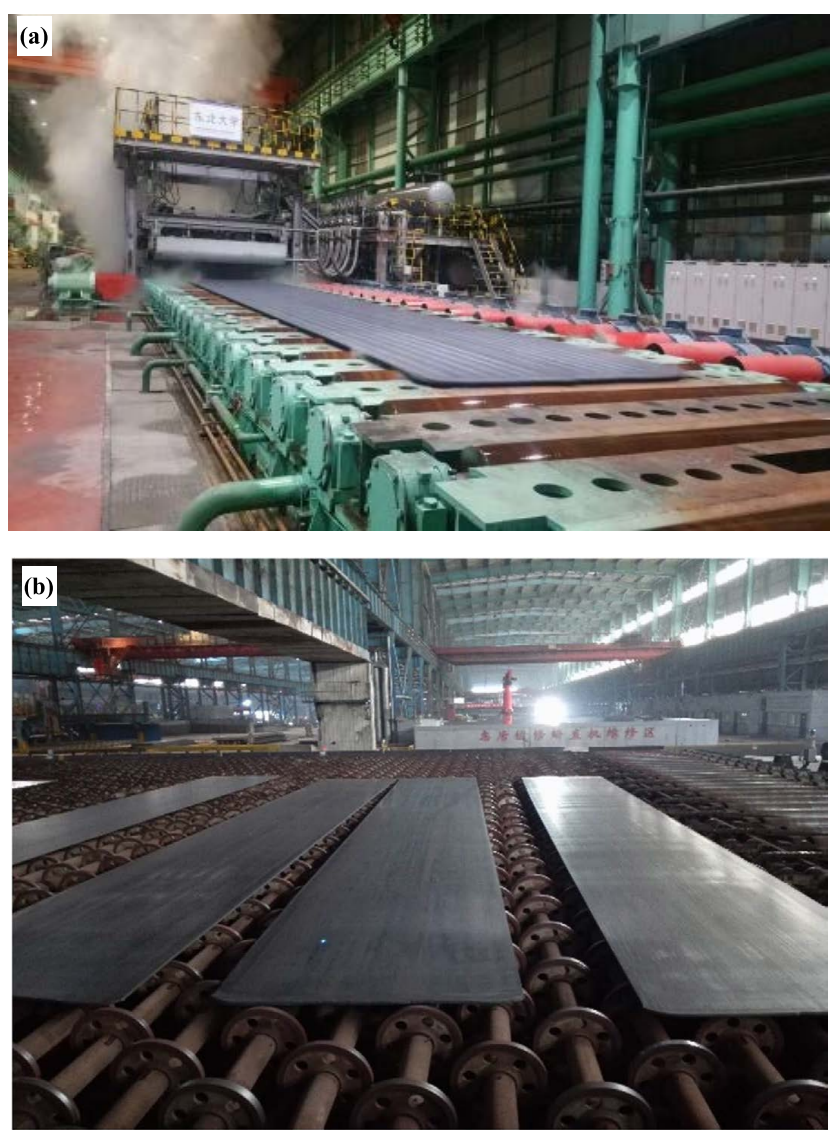

Fig. 7. Plate shape of high grade pipeline steel (a) and structural steel (b) developed by ADCOS system. (Online version in color.)

\section{Technical Principle and Industrial Application of NG-TMCP}

\subsection{Processing Principle and Strengthening Mecha- nism}

NG-TMCP was developed with the core technology of ultra fast cooling, which is effectively employed in high performance hot-rolled steels manufacturing and microstructure control, has broken through the cooling intensity limit of conventional TMCP with laminar cooling and the concept of strengthening by addition of a large number of alloying elements. NG-TMCP can be combined with large deformation and strain accumulation in continuous rolling, without the requirement for high reduction in the lower finish rolling temperature. For various microstructure and properties requirement, green strengthening concept of water in place of alloy is realized by increasing cooling rate and controlling the cooling route flexibly and precisely, exhibiting tremendous technical superiority in microstructure and properties control. ${ }^{27)}$

NG-TMCP technology has achieved innovative breakthrough in microstructure control mechanism and strengthening mechanism based on the advantage in grain refinement, precipitation and transformation control, realizing development and manufacturing of green high performance hot-rolled steel products. Schematic drawing for strengthening mechanism of NG-TMCP can be seen in Fig. 8 .

As for grain size control, UFC technology can realize grain refinement with the independence of alloying ele- (a)

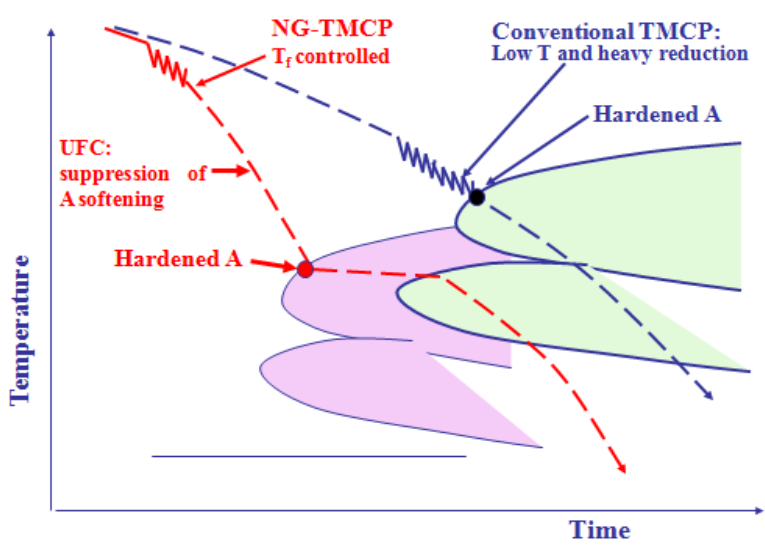

(b)

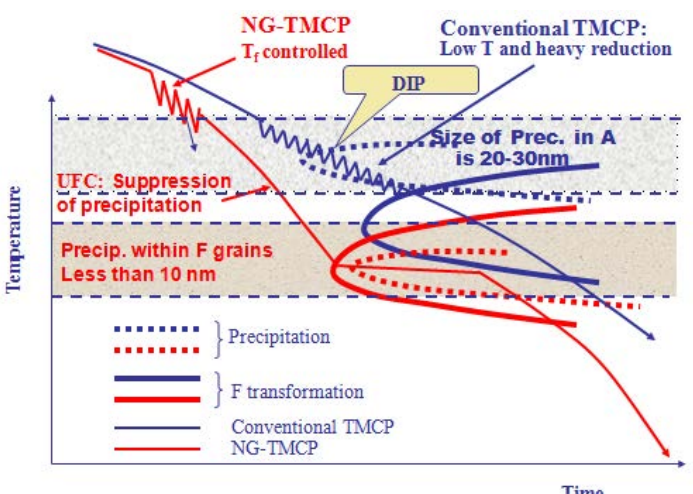

(c)

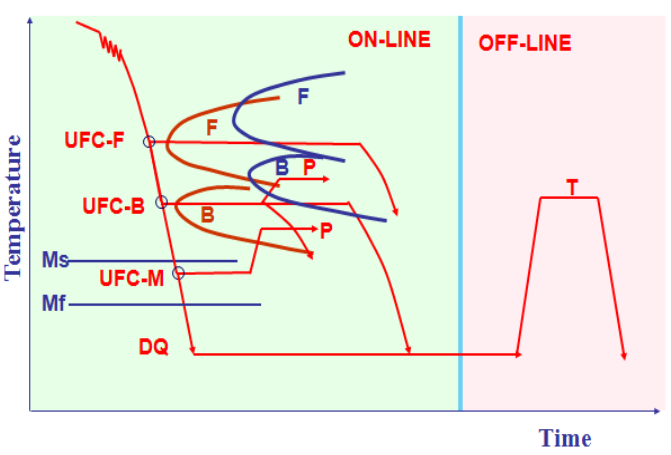

Fig. 8. Strengthening mechanism of NG-TMCP grain refinement strengthening, (b) precipitation strengthening and (c) transformation strengthening. (Online version in color.)

ments. For C-Mn steels with low alloy, stable fine grains can be obtained by greatly increasing cooling rate to avoid coarse grain or normal fine grain region and directly enter into the ultra-fine grain region, realizing stable enhancement of mechanical properties or reduction of alloying elements.

In precipitation control, NG-TMCP featured by UFC technology can properly increase finish rolling temperature and cooling rate after rolling, inhibit strain induced precipitation during hot rolling, and keep more microalloy elements into ferrite or bainite transformation region. Subsequently, precise cooling route is controlled and combined with a slow cooling treatment in order to obtain the optimum carbide precipitation process window.

Regarding the phase transformation control, ultra-fast cooling rate can inhibit austenite transformation at high temperature. For hot-rolled plate, by adopting UFC technology and controlling stop UFC temperature, hardened austenite 


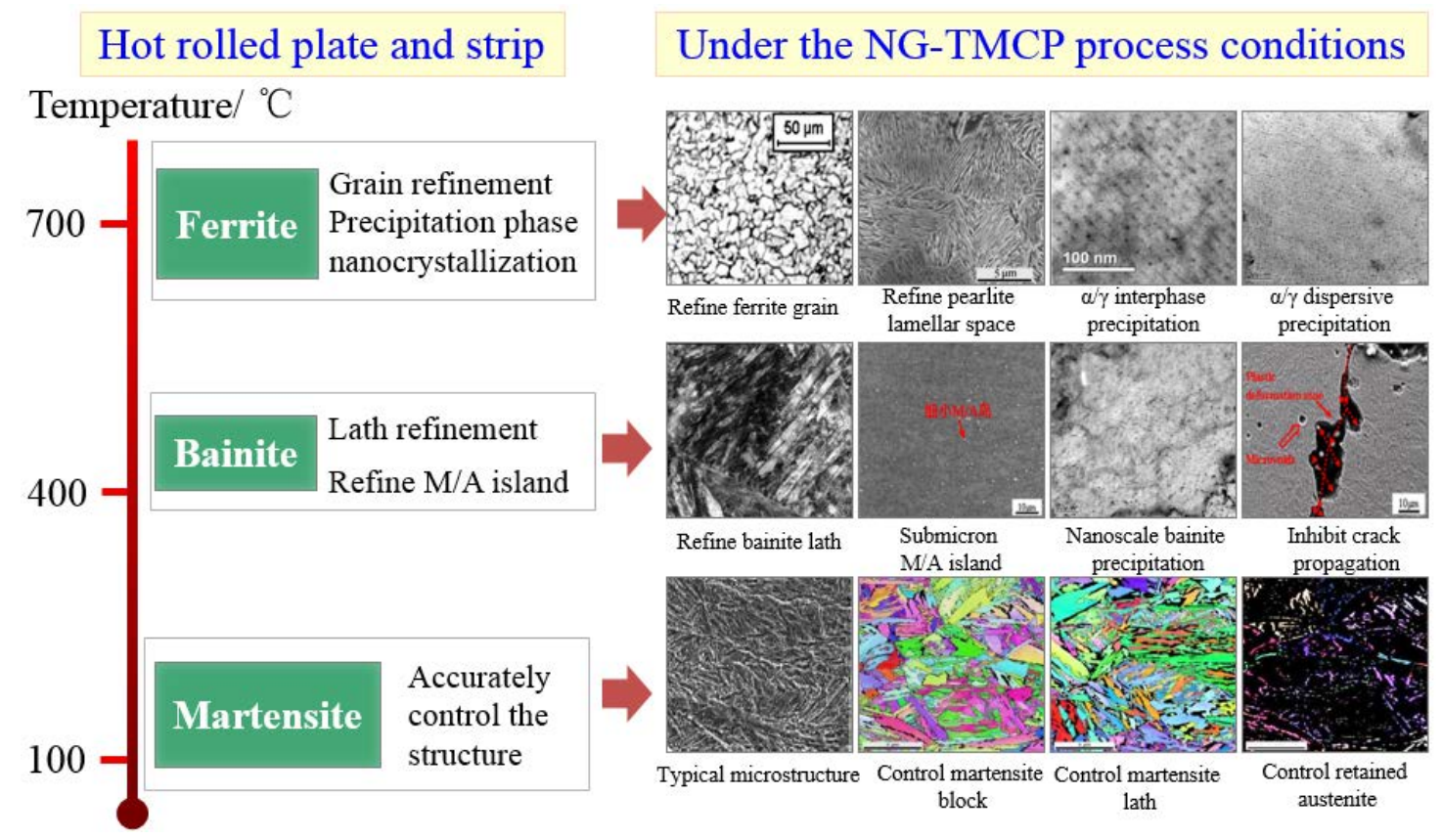

Fig. 9. Microstructure control principle for NG-TMCP. (Online version in color.)

Table 1. Applications of ADCOS in China in the recent 10 years.

\begin{tabular}{|c|c|c|c|c|c|c|}
\hline Company & Type & $\begin{array}{l}\text { Product } \\
\text { width } \\
(\mathrm{mm})\end{array}$ & $\begin{array}{l}\text { Product } \\
\text { thickness } \\
(\mathrm{mm})\end{array}$ & $\begin{array}{l}\text { Cooling zone length } \\
(\mathrm{m})\end{array}$ & Cooling technology & Date \\
\hline Wuyang Steel & Medium plate & 4100 & $5-100$ & 20 & $\mathrm{DQ} \backslash \mathrm{UFC} \backslash \mathrm{ACC}$ & 2019 \\
\hline Wukuang Group Yingkou Steel & Heavy plate & 5000 & $6-120$ & 30 & $\mathrm{DQ} \backslash \mathrm{UFC} \backslash \mathrm{ACC}$ & 2019 \\
\hline Shougang Group Jingtang Steel & Medium plate & 4300 & $5-100$ & $15(\mathrm{UFC})+15(\mathrm{ACC})$ & $\mathrm{DQ} \backslash \mathrm{UFC} \backslash \mathrm{ACC}$ & 2018 \\
\hline Shangang Group Rizhao Steel & Steckel mill & 3500 & $4-100$ & 34 & $\mathrm{DQ} \backslash \mathrm{UFC} \backslash \mathrm{ACC}$ & 2017 \\
\hline Shangang Group Rizhao Steel & Hot rolling strip & 2050 & $1.2-25.4$ & $20+15$ & $\mathrm{UFC} \backslash \mathrm{ACC}$ & 2017 \\
\hline Puyang Steel 2\# & Medium plate & 3500 & $5-100$ & 24 & $\mathrm{DQ} \backslash \mathrm{UFC} \backslash \mathrm{ACC}$ & 2016 \\
\hline Shagang Steel & Medium plate & 3500 & $5-100$ & $24,6(\mathrm{IPC}) \times 2$ & $\mathrm{DQ} \backslash \mathrm{UFC} \backslash \mathrm{ACC}, \mathrm{IPC}$ & 2016 \\
\hline Tangshan Steel & Medium plate & 3500 & $5-100$ & $24,6($ IPC $) \times 2$ & DQ $\backslash U F C \backslash A C C$, IPC & 2016 \\
\hline Nanjing Steel & Heavy plate & 5000 & $6-120$ & $6(\mathrm{IPC}) \times 2$ & IPC & 2015 \\
\hline Shagang Steel & Hot rolling strip & 1700 & $1.2-25.4$ & 15 & $\mathrm{UFC} \backslash \mathrm{ACC}$ & 2015 \\
\hline Shougang Group Jingtang Steel & Hot rolling strip & 2250 & $1.2-25.4$ & $20+10$ & $\mathrm{UFC} \backslash \mathrm{ACC}$ & 2014 \\
\hline Nanjing Steel & Heavy plate & 5000 & $5-150$ & 20 & $\mathrm{DQ} \backslash \mathrm{UFC} \backslash \mathrm{ACC}$ & 2014 \\
\hline Shaoguan Steel & Steckel mill & 3450 & $5-100$ & 24 & $\mathrm{DQ} \backslash \mathrm{UFC} \backslash \mathrm{ACC}$ & 2014 \\
\hline Baotou Steel & CSP & 1700 & $1.2-20$ & 10 & $\mathrm{UFC} \backslash \mathrm{ACC}$ & 2013 \\
\hline Xinyu Steel & Medium plate & 3800 & $5-100$ & 20 & $\mathrm{DQ} \backslash \mathrm{UFC} \backslash \mathrm{ACC}$ & 2013 \\
\hline Shougang Group Qiangang Steel & Hot rolling strip & 2160 & $1.2-25.4$ & 15 & $\mathrm{UFC} \backslash \mathrm{ACC}$ & 2012 \\
\hline Sanming Steel & Medium plate & 3000 & $6-80$ & 12 & $\mathrm{DQ} \backslash \mathrm{UFC} \backslash \mathrm{ACC}$ & 2011 \\
\hline Nanjing Steel & Medium plate & 2800 & $6-80$ & 20 & $\mathrm{DQ} \backslash \mathrm{UFC} \backslash \mathrm{ACC}$ & 2011 \\
\hline Ansteel & Medium plate & 4300 & $6-100$ & 7.2 & $\mathrm{DQ} \backslash \mathrm{UFC} \backslash \mathrm{ACC}$ & 2009 \\
\hline Shougang Group Shouqin Steel & Medium plate & 4300 & $5-100$ & 7.2 & DQ\UFC & 2009 \\
\hline Lianyuan Steel & CSP & 1700 & $0.8-12.7$ & 7 & $\mathrm{UFC} \backslash \mathrm{ACC}$ & 2008 \\
\hline Lianyuan Steel & Hot rolling strip & 2250 & $1.2-25.4$ & 10 & $\mathrm{UFC} \backslash \mathrm{ACC}$ & 2007 \\
\hline Puyang Steell\# & Medium plate & 3500 & $6-100$ & 7.2 & $\mathrm{DQ} \backslash \mathrm{UFC} \backslash \mathrm{ACC}$ & 2007 \\
\hline Jingye Steel & Medium plate & 3000 & $5-100$ & 4 & $\mathrm{DQ} \backslash \mathrm{UFC} \backslash \mathrm{ACC}$ & 2007 \\
\hline
\end{tabular}

UFC: Ultra fast cooling ACC: Accelerated cooling IPC: Inter-pass cooling DQ: Direct quenching 
can be kept into special transformation region, realizing microstructure control. UFC technology fully makes up for the shortcomings of traditional methods in the cooling path control, and a variety of microstructures can be obtained by phase transformation control. Figure 9 shows the technological foundation for controlling the performance of diversified microstructures.

At present, UFC-F, UFC-B and UFC-M ultra-fast cooling online heat treatment processes have been developed, which realized precise control of ferrite, bainite and martensite microstructure. These processes have been applied to production of low-cost alloy steel, high grade pipeline steel, engineering machinery steel, abrasion resistant steel and high quality Quench \& Partitioning (Q\&P) steel.

\subsection{Application of Industrial Equipment and Product}

The flexibility in on-line heat treatment technology can be obtained by using ADCOS technology with the benefit of high cooling rate, large-range adjustment, accurate temperature control and cooling profile control. Under this condition, a variety of cooling modes can be accomplished, including accelerated cooling (ACC), ultra-fast cooling (UFC), dual stage cooling (DC), direct quenching (DQ, $\mathrm{UFC}+\mathrm{M}$ ), direct quenching \& partitioning (DQP), and interrupted direct quenching (IDQ).

As seen in Table 1, with the further mature and improvement of ADCOS technology, the advanced cooling equipment developed by RAL has been applied widely in
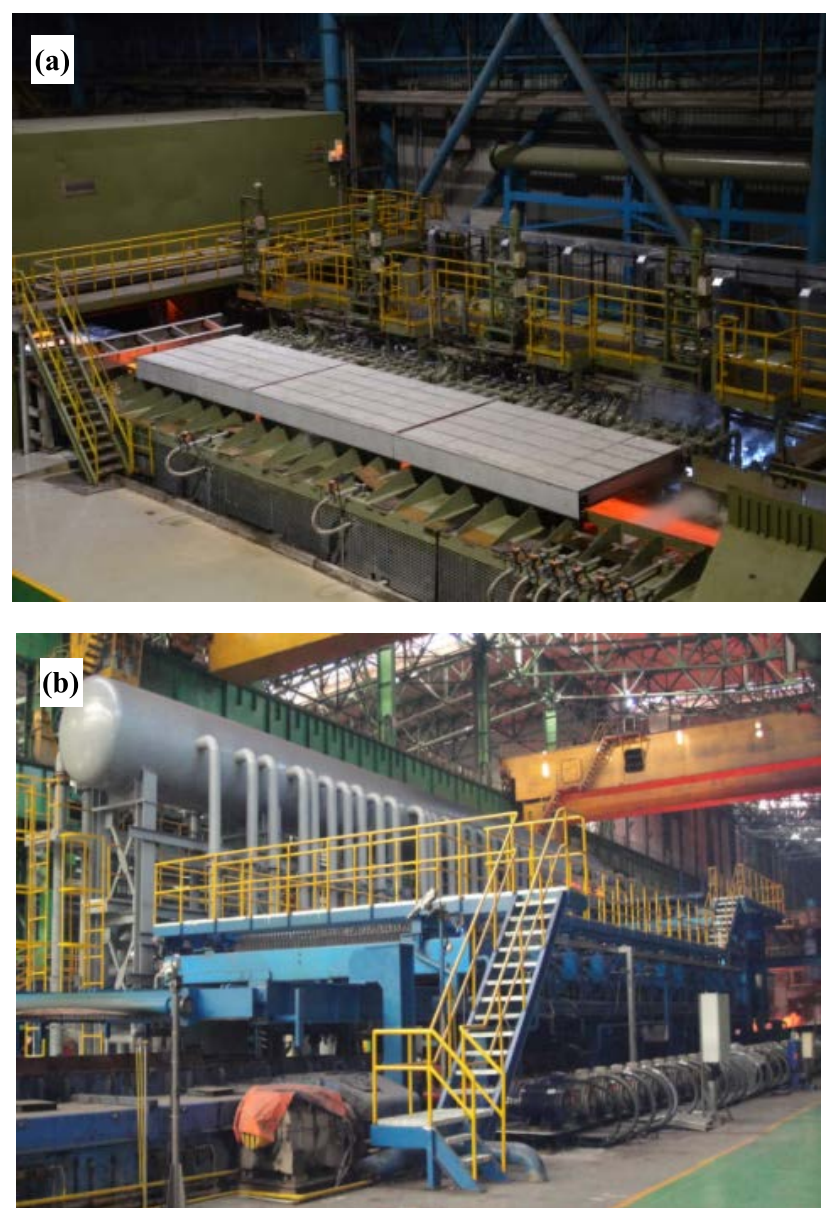

Fig. 10. ADCOS system for hot-rolled strips (a) and plates (b). (Online version in color.) more than 20 production lines for plate and strip steels, such as $2250 \mathrm{~mm}$ in Lianyuan steel, $2160 \mathrm{~mm}$ and 2250 $\mathrm{mm}$ in Shougang Group, CSP in Baotou steel, $5000 \mathrm{~mm}$ in Nanjing steel, $3450 \mathrm{~mm}$ in Shaoguan steel, $3500 \mathrm{~mm}$ in Shagang Group and so on. ADCOS technology and equipments for hot rolling strips and plates were shown in Fig. 10.

The NG-TMCP with UFC technology has been extensively used in the field of hot-rolled strip and plate, which fully makes up for the shortcomings of traditional methods in the cooling path control, and a variety of products can be obtained by phase transformation control. A series of high-strength low-alloy steels with benefits of alloy reduction, value-added pipeline steels, and high performance steels were developed successfully by using ADCOS system.

\subsubsection{Low Alloy Ferrite/pearlite Steel}

For low alloy ferrite/pearlite steels, the application of UFC technology further refines the grain size and diminishes banding microstructure, as shown in Fig. 11. The mechanical properties of products can be significantly improved by the use of fine grain strengthening, with the aim to reduce the consumption of alloying elements and make the steel making process economically viable. For instance, commercial low carbon steel ASTM A572Gr50 with no Nb-content added and Mn-content reduced by $20-30 \%$ is developed by ADCOS system, and save more 40-60 RMB (Chinese yuan)
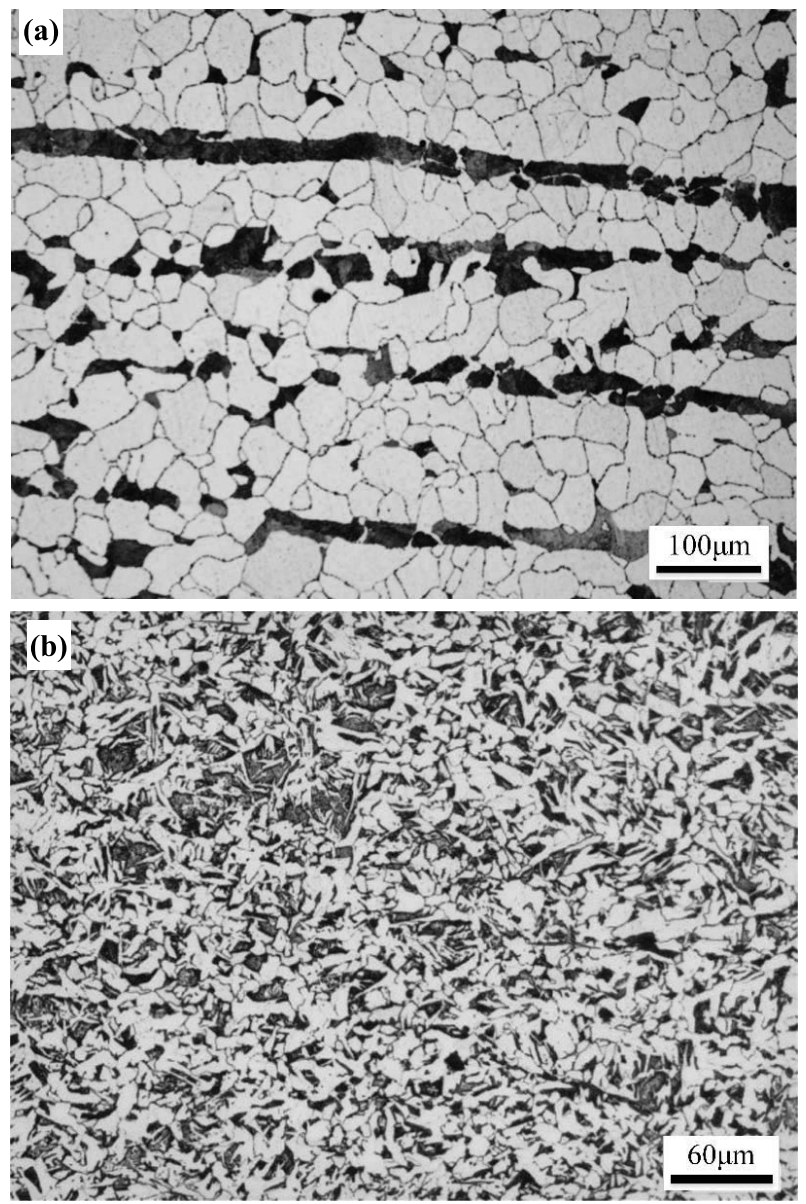

Fig. 11. Optical micrographs of C-Mn structural steel plate after $\mathrm{ACC}(\mathrm{a})$ and UFC (b) process. 
per ton compared with conventional products. For low alloy structural steels with a yield strength of less than $460 \mathrm{MPa}$, such as bridge plate, construction steel, ship plate and pressure vessel plates, the comprehensive mechanical properties are also improved effectively.

\subsubsection{Bainite Steel Product}

For bainite steel products, a significant advantage of UFC technology is to control the phase morphology, size and precipitation of bainite. The high-cost alloy elements, such as Mo and $\mathrm{Nb}$, can be reduced in composition and the comprehensive mechanical properties are greatly improved by the combination of fine grain strengthening, acicular ferrite phase transformation strengthening and precipitation strengthening. The series of high quality pipeline steel X65-X80, high strength engineering machinery steel and petroleum storage tank steel product have been realized in mass industrial production by using UFC technology. Meanwhile, low-cost high-strength steel with lower carbon equivalent, improved welding performance significantly, as shown in Fig. 12.

\subsubsection{Martensite Steel Product}

The on-line direct quenching in hot rolling production line can be realized due to the high cooling capacity of ADCOS system, as shown in Fig. 13, providing a saving-type mode of production process for high grade engineering machinery

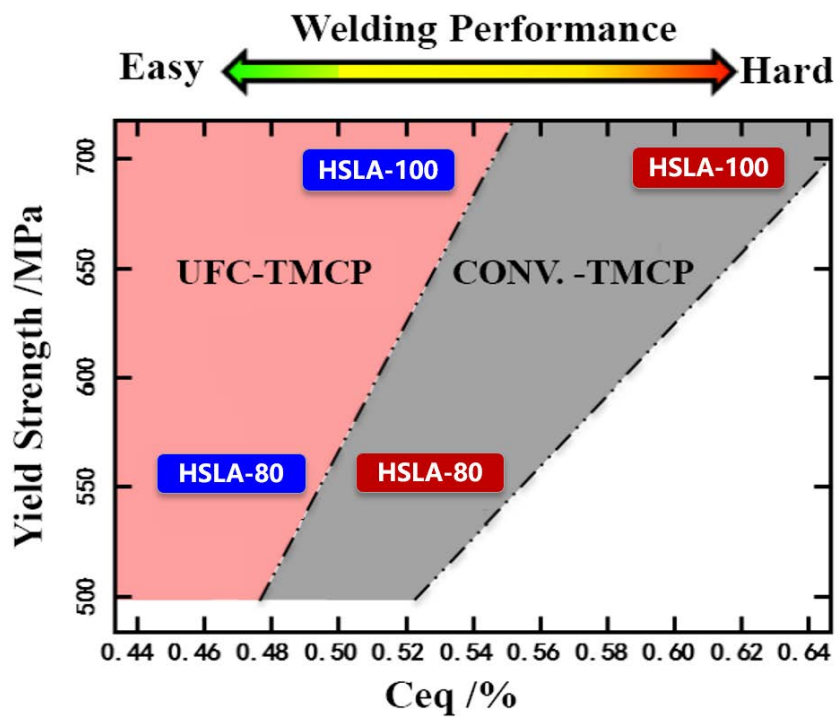

Fig. 12. The relationship between welding performance, strength and carbon equivalent. (Online version in color.)

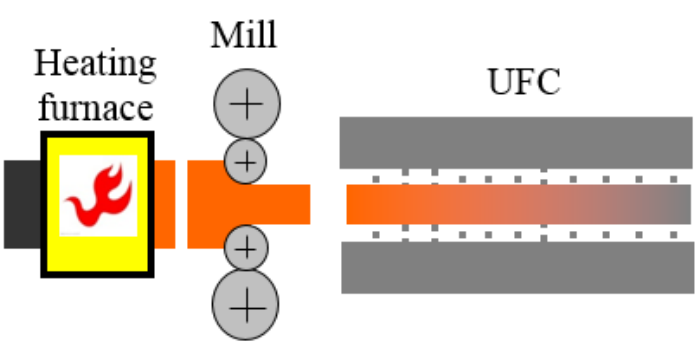

steel, wear-resistant steel, Q\&P steel and other martensite products. On-line $\mathrm{DQ}+\mathrm{T}$ technology replacing off-line $\mathrm{Q}+\mathrm{T}$ mode can not only save the cost of the secondary
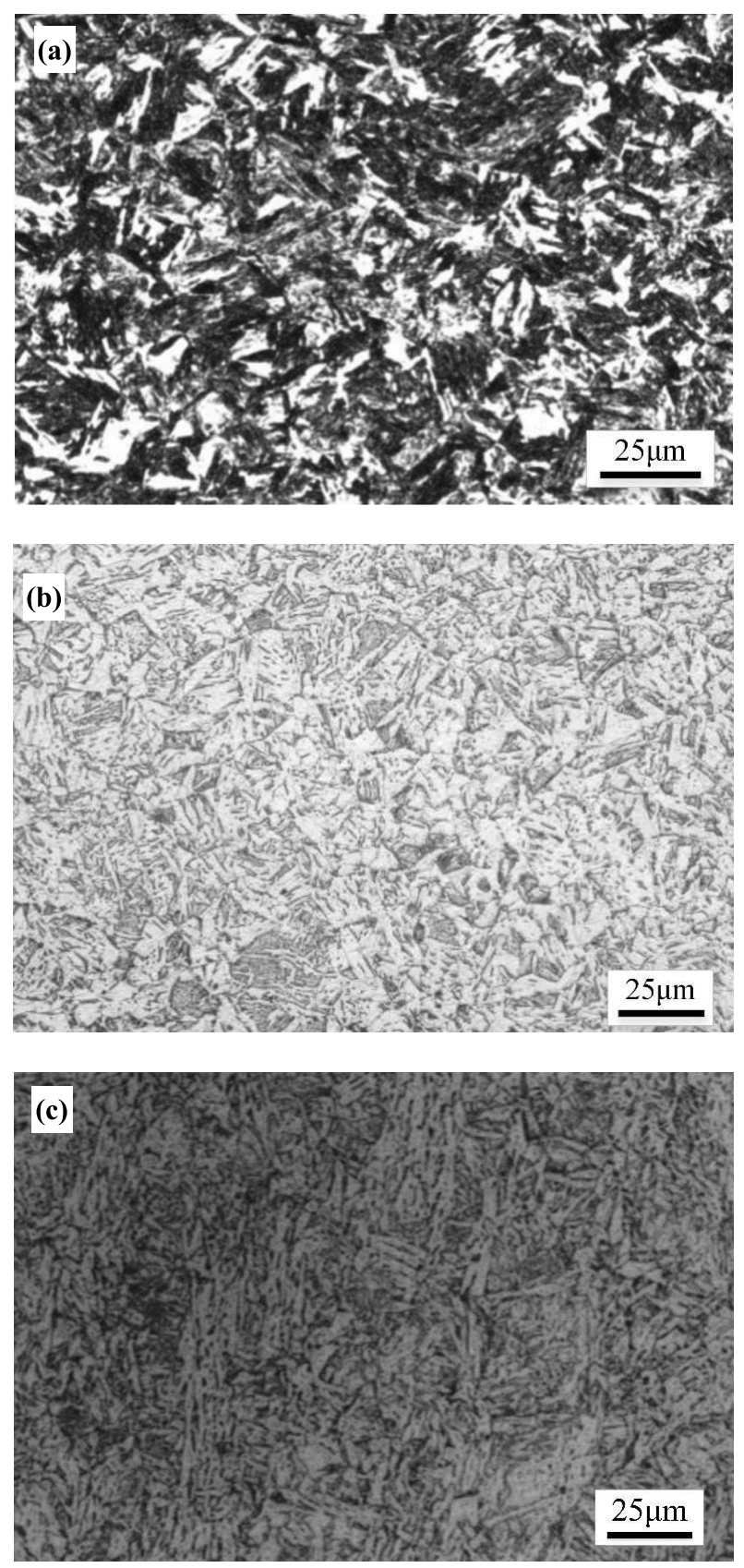

Fig. 14. Martensite structure in on-line direct quenching process (a) Wear-resistant steel (b) Low-cost hydropower steel (c) Oil storage tank steel.

\section{Free off-line heating-quenching}

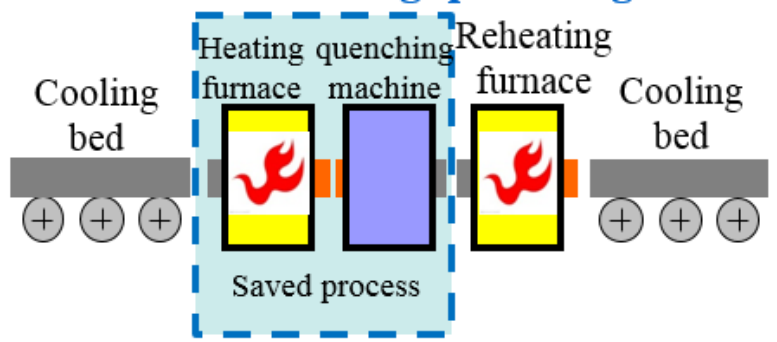

Fig. 13. Simplification in on-line $\mathrm{DQ}+\mathrm{T}$ process. (Online version in color.) 
reheating, but also make full use of the cumulative deformation energy and dislocation defects during controlled rolling and increase nucleation sites in the subsequent cooling process. Therefore, UFC technology provides a low-cost method of achieving uniform and refined microstructure to improve the mechanical properties of martensite products. Figure 14 shows the type microstructure in on-line direct quenching process.

\subsubsection{Dual Phase Steel Product}

The postposition-type UFC technology has been also applied in continuous production line for high quality dual phase steel product. Based on the high efficiency of cooling capacity and high precision control of cooling path, DP540 and DP590 were realized in bulk supply by adopting the low cost $\mathrm{C}-\mathrm{Mn}$ composition system. The microstructural proportion control of the product is reasonable and stable, and the mechanical properties are excellent, making the strength fluctuation in range of $25 \mathrm{MPa}$. At present, a series of high quality hot rolled dual phase steel products have been developed with the thickness of 3-13 $\mathrm{mm}$ and the strength of 540-780 MPa, because of the effective ACC and UFC path control. Figure 15 shows the microstructure and $180^{\circ}$ cold-bend test sample for $11.0 \mathrm{~mm}$ thickness DP590 steel.
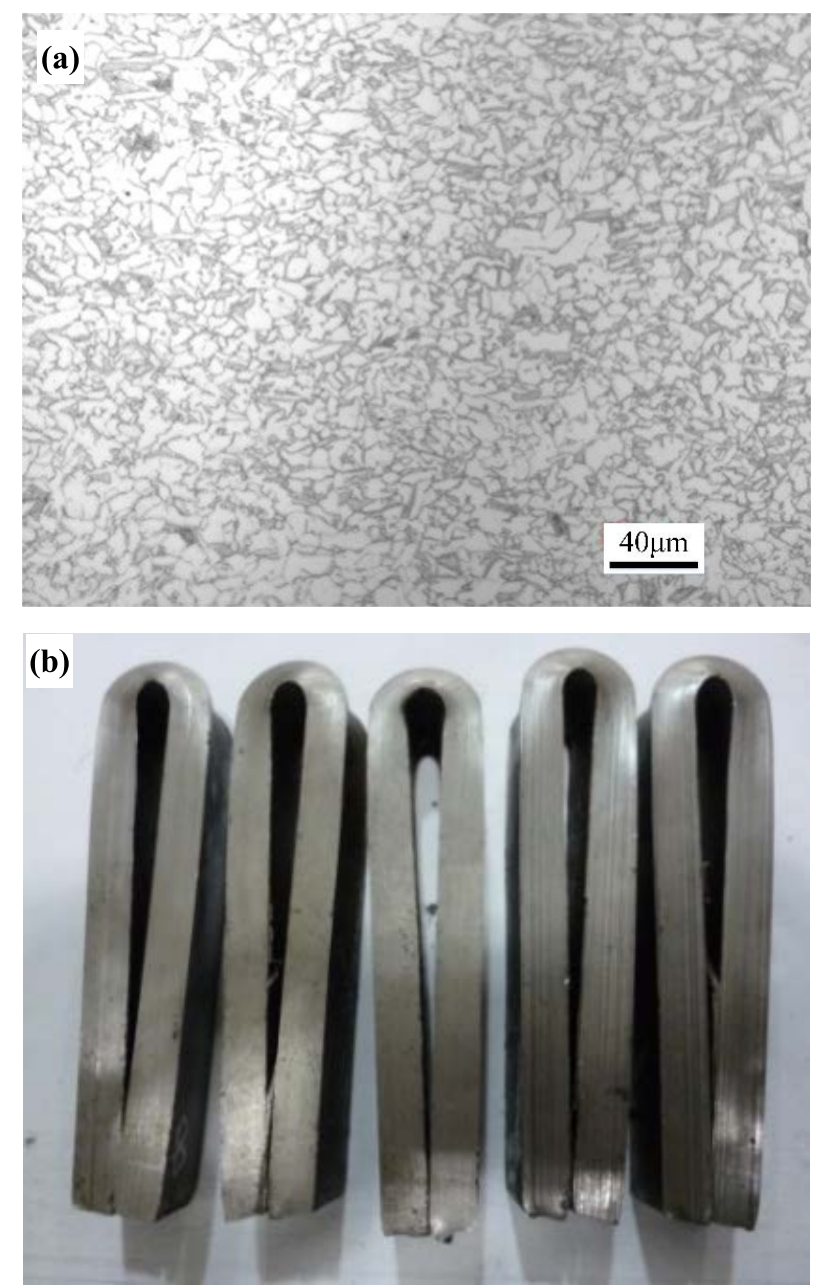

Fig. 15. The microstructure (a) and $180^{\circ}$ cold-bend test sample (b) of DP590 steel. (Online version in color.)

\section{Development and Application of Rolling with Inter- pass Cooling Technology}

Coordination and control of reduction and temperature is the core technology for hot rolling process. The novel interpass cooling (IPC) technology combines rolling and cooling devices to realize the effective synchronization of rolling and cooling process. Specifically, work piece can be water cooled by using water cooling device near the mill for adjusting the temperature of steel slab effectively between rolling passes. ${ }^{28)}$ The "rolling-cooling" synchronous technology has obvious advantages for increasing deformation penetration and developing the fine-grain structure in the surface of plate. Schematic illustration of Inter-pass cooling is shown in Fig. 16.

The water cooling in the midst of rolling can lead to the large temperature gradient through the slab thickness. ${ }^{29,30}$ Due to the low temperature and high deformation resistance in the surface, the surface metal deforms more difficultly and the deformation of internal metal is enhanced in the same rolling load. The comparison between IPC process and conventional TMCP of heavy EH47 plate has been studied, and grain refinement of heavy plate are improved obviously, due to the high deformation penetration. The acicular ferrite fractions at 1/2-thickness of the IPC and TMCP steels are $50 \%$ and $9.5 \%$, respectively. The granular bainite width at 1/2-thickness of the IPC steel was $14 \pm$ $4 \mu \mathrm{m}$, which is significantly lower than the TMCP steel $(27 \pm 10 \mu \mathrm{m}),{ }^{31)}$ as shown in Fig. 17. Nowadays, rolling with inter-pass cooling technology has been applied to Nanjing Steel $5000 \mathrm{~mm}$, Tangshan Steel $3500 \mathrm{~mm}$ and Shagang Group $3500 \mathrm{~mm}$, and the internal deformation of heavy plate can be enhanced for improving equality. Figure 18(b) shows macroscopic shapes of the plate side through thickness of conventional rolling and Inter-pass cooling processing. The side-surface shape at the lateral plate end in conventional rolling process shows double bulge and the disparity of lengthwise displacement between top and bottom of bulge is $2.0 \mathrm{~mm}$. Meanwhile, It can be found the similar double bulge at the end of plate in IPC process, and the extended difference of bulge through thickness is 1.0 $\mathrm{mm}$. It indicates that the deformation penetration deepens into the core area of the plate and the internal metal flow enhances in IPC process. ${ }^{30}$ )

Inter-pass cooling technology is characterized by the accelerated cooling in the midst of rolling followed by

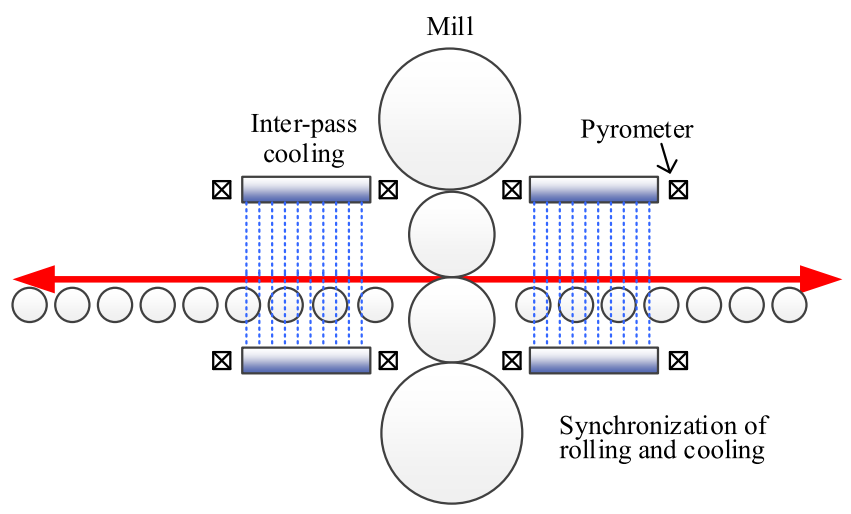

Fig. 16. Schematic illustration of Inter-pass cooling and UFC process. (Online version in color.) 
(a)

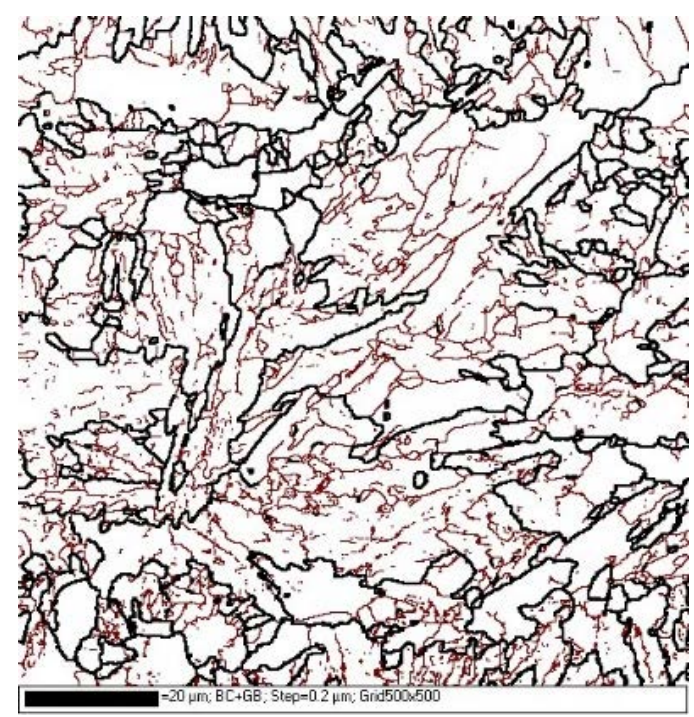

(b)

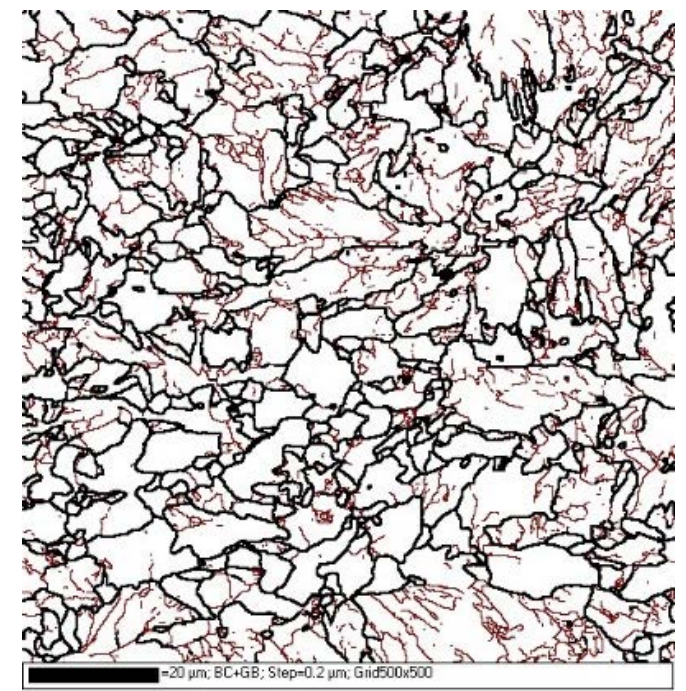

Fig. 17. Misorientation maps of ship plate EH47 at 1/2-thickness by (a) TMCP and (b) IPC+TMCP. (Online version in color.)

controlled rolling in the reheating process. Ferrite grains are refined by their recovering and recrystalllzing due to highly accumulated dislocatlons through hot deformation and increased ferrite nucleation by reheating supercooled austenite owing to the sufficient driving force for austenite to ferrite transformation. ${ }^{32)}$ Fine-grained microstructure in the surface layer is shown in Fig. 19. Mechanical properties of steel plate are extremely improved due to the ultra fine grains in surface layers. The rolling with inter-pass cooling technology can be used for the research and development of container ship plate with high crack arresting performance, pressure vessel plate with high strength, pipeline steel with large deformation resistance, and other high value-added products.

\section{Conclusions}

The NG-TMCP with UFC technology makes up for the shortcomings of traditional methods in the cooling path control, and provides high cooling capacity and uniform cooling control for a wide range of water-cooled steel strips and plates, such as construction steel, bridge plate, ship plate,

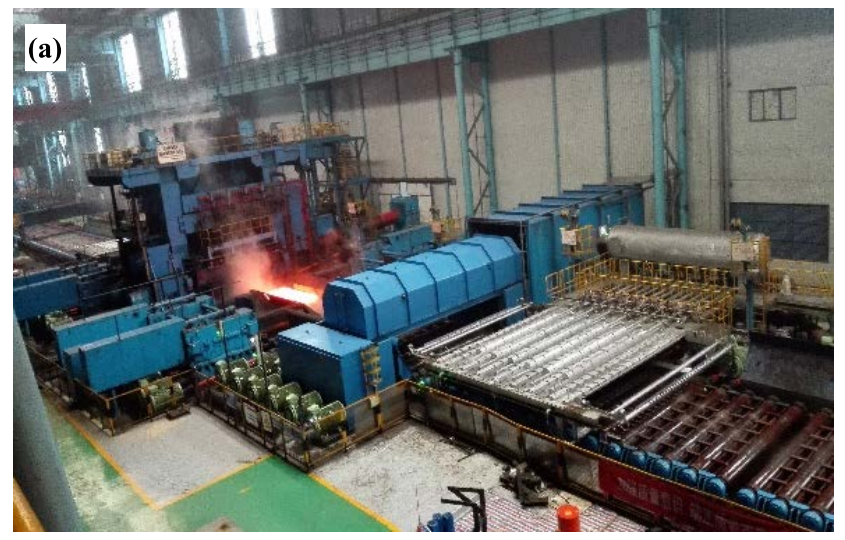

(b)

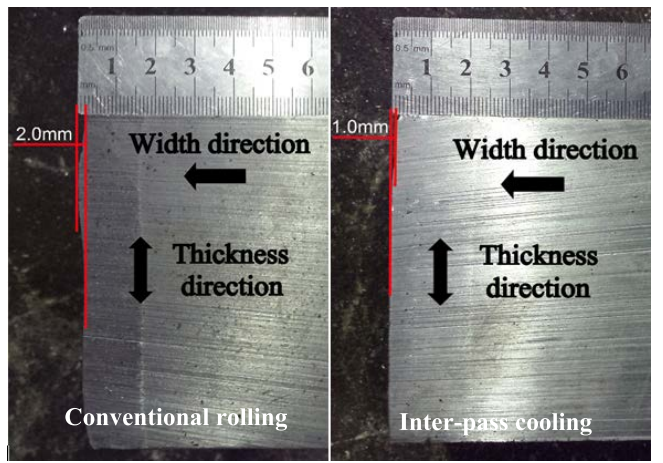

Fig. 18. Inter-pass cooling device in Nanjing steel (a) and its heavy penetration effect (b). (Online version in color.)
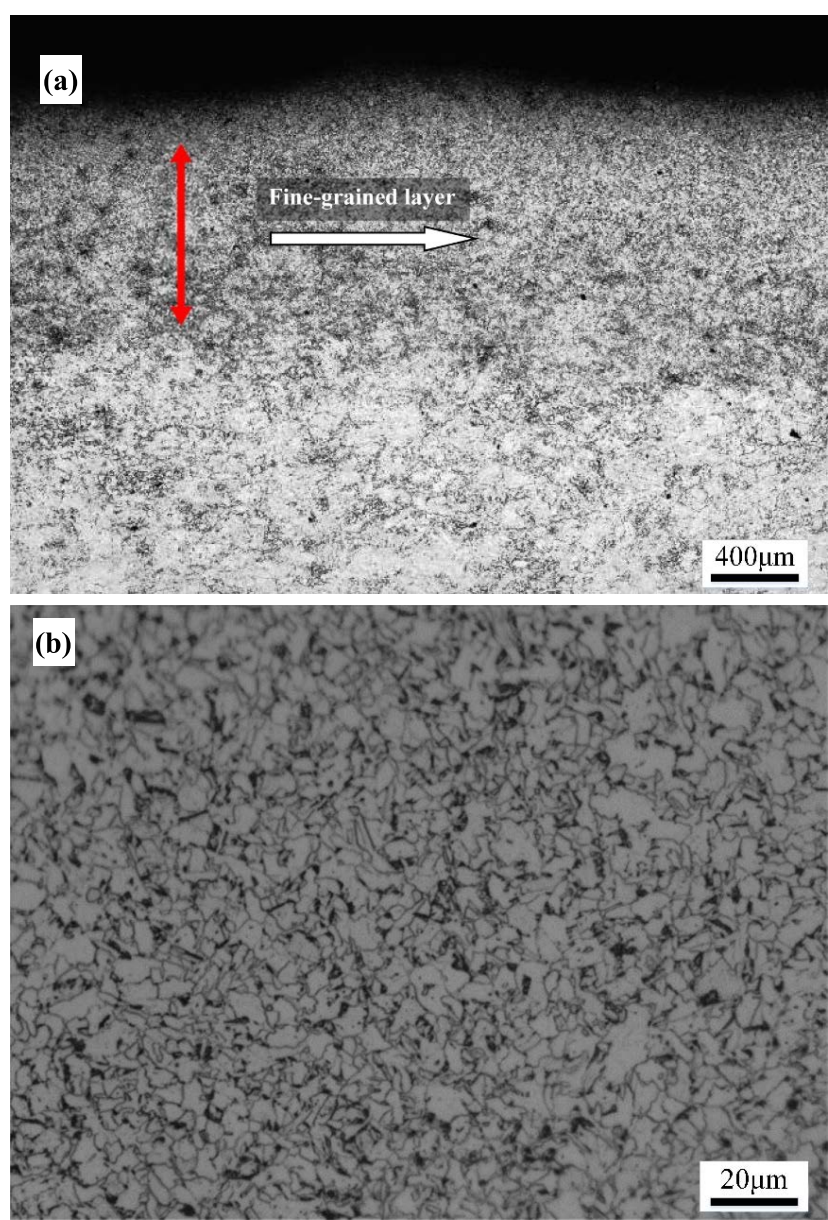

Fig. 19. Fine-grained microstructure in the surface layer by interpass cooling technology. (Online version in color.) 
pipeline steel, engineering machinery steel, pressure vessel steel, Q\&P steel, and so on.

With the further mature and improvement of ADCOS technology, the advanced cooling equipment developed in China has been applied widely in steel industry, for enormous reduction in alloy-addition, considerable simplification in the process and improvement in mechanical properties.

Inter-pass cooling technology is characterized by watercooling between controlled rolling passes and further reheating due to the internal heat capacity of plates themselves. Fine-grained microstructure in the surface layer of plate is obtained to extremely improve the mechanical properties and as well as application performance.

\section{Acknowledgements}

This work was supported financially by National Key Research and Development Program of China (2017YFB0305301 and 2016YFB0300602), National Natural Science Foundation of China (51604074), and Fundamental Research Funds for the Central Universities (N170704012) respectively.

\section{REFERENCES}

1) G. D. Wang: Shanghai Met., 30 (2008), 1 (in Chinese).

2) A. Lucas, P. Simon, G. Bourdon, J. C. Herman, P. Riche, J. Neutjens and P. Harlet: Steel Res. Int., 75 (2004), 139.

3) K. Nishioka and K. Ichikawa: Sci. Technol. Adv. Mater., 13 (2012), 023001.

4) S. Endo and N. Nakata: JFE Tech. Rep., 20 (2015), 1.

5) P. Simon, J. P. Fishbach and P. Riche: Rev. Metall., 93 (1996), 409.

6) H. J. Li, Z. L. Li, G. Yuan, Z. D. Wang and G. D. Wang: J. Iron Steel Res. Int., 20 (2013), 29.

7) G. D. Wang, X. H. Liu, L. G. Sun, Z. Liu and D. Q. Liu: Iron Steel, 43 (2008), 49 (in Chinese).
8) X. H. Liu, G. F. She, J. M. Qiao, Z. P. Zhang, L. G. Peng and G. D. Wang: Iron Steel, 39 (2004), 71 (in Chinese).

9) G. Buzzichelli and E. Anelli: ISIJ Int., 42 (2002), 1354.

10) K. E. Hensger: Metalurgija, 41 (2002), 183.

11) Y. Funakawa, T. Shiozaki, K. Tomita, T. Yamamoto and E. Maeda: ISIJ Int., 44 (2004), 1945.

12) K. Seto, Y. Funakawa and S. Kaneko: JFE Tech. Rep., 10 (2007), 19.

13) A. Fujibayashi and K. Omata: JFE Tech. Rep., 5 (2005), 10.

14) Y. Tian, S. Tang, B. X. Wang, Z. D. Wang and G. D. Wang: Sci. China (Tech. Sci.), 55 (2012), 1566.

15) K. Omata, H. Yoshimura and S. Yamamoto: NKK Tech. Rev., 88 (2003), 73.

16) JFE Steel: JFE Tech. Rep., 1 (2003), 15.

17) P. Paisley: metals \& mining, 1 (2007), 38

18) L. Pichler, K. Weinzierl and S. Samanta: 53rd Rolling, Processose Produtos Laminados e Revestidos, part of the ABM Week, (Brazil), (2016), https://pdfs.semanticscholar.org/7de0/890472aae1c645d887 df1737648062d652c6.pdf, (accessed 2019-06-04).

19) Siemens wins order for Mulpic intensive plate cooling system from China Steel in Taiwan, Siemens: Press Release, https://www.siemens. com/press/photo/IMT201405649-01e, (accessed 2019-01-12).

20) B. X. Wang, Y. Tian, G. Yuan, Z. D. Wang, G. D. Wang and J. Chen: Adv. Mater. Res., 189-193 (2011), 2515.

21) B. X. Wang, X. L. Chen, Y. Tian, Z. D. Wang, J. Wang and D. H. Zhang: J. Iron Steel Res. Int., 28 (2011), 38.

22) B. Wang, Z. Y. Liu, X. G. Zhou, G. D. Wang and R. D. K. Misra: Mater. Sci. Eng. A, 575 (2013), 189.

23) E. Y. Liu, L. G. Peng, G. Yuan, Z. D. Wang, D. H. Zhang and G. D. Wang: J. Cent. South Univ., 19 (2012), 1341.

24) B. X. Wang, Q. Xie, Z. D. Wang and G. D. Wang: J. Cent. South Univ., 11 (2013), 2690.

25) N. Karwa, T. G. Roisman, P. Stephan and C. Tropea: Exp. Therm. Fluid Sci., 35 (2011), 1435.

26) T. Azuma and T. Hoshino: Trans. Jpn. Mech. Eng., 50 (1984), 974.

27) G. D. Wang: China Metall., 22 (2012), 1 (in Chinese).

28) S. Tsuyama: ISIJ Int., 55 (2015), 67.

29) W. Yu, G. S. Li and Q. W. Cai: J. Mater. Process. Technol., 217 (2015), 317.

30) T. Zhang, B. X. Wang, Z. D. Wang and G. D. Wang: ISIJ Int., 56 (2016), 179.

31) J. Y. Wu, B. Wang, B. X. Wang, R. D. K. Misra and Z. D. Wang: Mater. Sci. Eng. A, 733 (2018), 117.

32) J. Y. Wu, B. Wang, B. X. Wang and Z. D. Wang: J. Northeast. Univ. (Nat. Sci.), 39 (2018), 1582 (in Chinese). 